3 US Department of Health and Human Services. The lipid research clinics: population studies date book. Washington, DC. National Institutes of Health, Public Health Service, 1980. (No book. Washin.
80-1537.)

4 Hulley S, Rosenman R, Bawol R, Brand R. Epidemiology as a guide to clinical decisions: the association between triglyceride and coronary heart disease. N Engl f Med 1980;302:1383-9.

Avins AL, Haber RJ, Hulley SB. The status of hypertriglyceridemia as a risk factor for coronary heart disease. Clin Lab Med 1989;9:153-68.

6 Sackett DS, Haynes RB, Guyatt GH, Tugwell P. Clinical epidemiology: a basic science for clinical medicine. 2nd ed. Boston: Little, Brown, 199

Oliver $M$. Risks of correcting the risks of coronary disease and strokes with drugs. $N$ Engl $\mathcal{F}$ Med 1982;306:297-8

8 Shepherd J, Krauss R. Pathophysiology of triglyceride-rich particles. A. Metabolism of triglyceride-rich particles. Am f Cardiol 1991;68:5-7A.

9 Stein Y, Havel RJ. Pathophysiology of triglyceride-rich particles. B. Triglyceride-rich lipoprotein cell interactions. Am F Cardiol 1991;68:8-10A.

10 Austin MA, Goto Y, Lenfant C, Tyroler HA. The hypertriglyceridemias: risk and management. Epidemiology. Am $\mathcal{f}$ Cardiol 1991;68:22-5A.

11 Muldoon M, Manuck S, Matthews K. Lowering cholesterol concentrations and mortality: a quantitative review of primary prevention trials. $B M$ f 1990;301:309-14.

12 Newman TB, Browner W, Hulley SB. Childhood cholesterol screening: contraindicated. FAMA 1992;267:100-1.

13 Carlson LA, Rosenhamer G. Reduction of mortality in the Stockholm ischaemic heart disease secondary prevention study by combined treatment with clofibrate and nicotinic acid. Acta Med Scand 1988:223:405-18.

14 Lipid Research Clinics Program. Lipid Research Clinics primary prevention trial results: II. The relationship of reduction in incidence of coronary heart disease to cholesterol lowering. FAMA 1984;251:365-74.
15 Levy RI, Brensike JF, Epstein SE, Kelsey SF, Passomani ER, Richardson JM, et al. The influence of changes in lipid values induced by cholestyramine and diet on progression of coronary artery

16 Canner PL, Berge KG, Wenger NK, Stamler J, Friedman L, Prineas RJ, et al. Fifteen year mortality in coronary drug project patients: long-term benefit with niacin. $\mathcal{F}$ Am Coll Cardio 1986;8:1245-55.

17 Manninen V, Hutrunen JK, Heinonen OP, Tenkanen L, Frick MH. Relation between baseline lipid and lipoprotein values and the incidence of coronary heart disease in the Helsinki heart study. Am f Cardiol 1989;63:42-7H

18 Davis C, Haesook K. Is triglyceride level an independent risk factor for CHD? Circulation 1990;81:725

19 Barrett-Connor E, Bush TL. Estrogen replacement and coronary heart disease. Cardiovasc Clin 1989;19:159-72.

20 Stampfer MJ, Colditz GA. Estrogen replacement therapy and coronary heart disease: a quantitative assessment of the epidemiologic evidence. Prev Med 1991;20:47-63.

21 National Cholesterol Education Program Expert Panel on Detection, Evaluation, and Treatment of High Blood Cholesterol in Adults. Report. Arch Intern Med 1988;148:36-69.

22 Gotto A, Paoletti R. Atherosclerosis reviews. Vol 22. New York: Raven Press, 1991.

23 Hayward RSA, Steinberg EP, Ford DE, Roizen MF, Roach KW. Preventive care guidelines. Ann Intern Med 1991;114:758-83.

24 US Preventive Services Task Force. Guide to clinical preventive services: an assessment of the effectiveness of 169 interventions: report of the US Preventive Services Task Force. Baltimore: Williams and Wilkins, 1989 .

25 Garber AM, Sox HJ, Littenberg B. Screening asymptomatic adults for cardiac risk factors: the serum cholesterol level. Ann Intern Med 1989;110:622-39.

26 Toronto Working Group on Cholesterol Policy. Asymptomatic hypercholesterolemia: a clinical policy review. $\mathcal{f}$ Clin Epidemiol 1990;43:1028-121.

\title{
Liver transplantation in children
}

The improved outcome after liver transplantation in children, reported by Salt and colleagues in this issue ( $p 416),{ }^{1}$ results from many advances in management. For instance, better, safer immunosuppression has reduced the incidence of acute rejection, and better preservation solutions now permit extended cold ischaemia without sacrificing organ function. But the most important advances in liver transplantation in children have been in the selection of patients and surgical technique.

A trend towards earlier referral has developed as results with liver replacement have improved. In the past much of the mortality before transplantation was attributable to referrals that were made too late. In the series from Cambridge and King's College Hospital almost one in five children waiting for an organ died before receiving it. ' Referral for transplantation should be considered if the child has deteriorating hepatic synthetic function (coagulopathy, hyperbilirubinaemia, or hypoalbuminaemia), complications related to portal hypertension (variceal haemorrhage, ascites, or hypersplenism), inborn metabolic defects with risk of irreversible complications (malignancy or neurological or other organ damage), or cholestasis with growth failure despite nutritional treatment.

Biliary atresia continues to be the main indication for liver replacement, the remaining recipients comprising children with cholestatic liver diseases (for example, Alagille's syndrome), inborn errors of metabolism (for example, $\alpha_{1}$-antitrypsin deficiency and Wilson's disease), and a heterogeneous group of other liver diseases. For biliary atresia it has been suggested that liver transplantation should replace Kasai's portoenterostomy operation as the best treatment. ${ }^{2}$

Proponents of this approach argue that the Kasai procedure increases the technical difficulty, blood loss, and mortality with subsequent transplantation, but this has not been clearly established. In fact, the transplant group from the University of Nebraska found no increase in operative time, blood loss, morbidity, or mortality among children coming to transplantation after Kasai's operation compared with other recipients. ${ }^{3}$ Additionally, many patients having portoenterostomy for biliary atresia will achieve long term survival and avoid lifelong immunosuppression (about half the patients survive five years; one quarter to one third of patients survive to adolescence) ${ }^{4}$ Without the Kasai procedure most infants with biliary atresia will not survive beyond the first or second year of life. Donors in this age group are scarce, and survival after liver transplantation in infancy is still lower than in older children. ${ }^{5}$ It seems, therefore, that transplantations should not replace Kasai's operation but rather should be complementary.

Liver transplantation in children differs fundamentally from the operation in adults because of problems with biliary reconstruction. In most children the common bile duct of the recipient is unusable for duct to duct anastomosis because it is either congenitally absent (as in biliary atresia) or too small to accept a T tube. Biliary reconstruction by choledochojejunostomy has greatly reduced the incidence of bile leaks and strictures. The series published today confirms this point: "direct anastomosis of the common bile duct to a Roux loop was associated with fewer complications than the three other types of anastomosis (5\% compared with $21-32 \%$ )."

The most revolutionary technical change in the operation in children has been the widespread use of reduced size donor allografts. ${ }^{67}$ Using only portions of the liver expands the pool of potential donors for children. Unfortunately, this technique only "borrows" donors from the adult pool, where the shortage of donors is not quite as acute. It does not increase the overall number of organs unless one organ is divided between two recipients. The penalty for using one donor liver for two recipients is increased complications and reduced survival. ${ }^{8}$ Conversely, living donors (usually parents) may provide a new source of grafts that does not further strain the network of organ distribution. The results in the first 20 children who received liver transplants from living donors at the University of Chicago are similar to those in children who received cadaveric organs. ${ }^{9}$ These new surgical techniques, along with advances in management before and after the operation, promise to improve further the results of liver transplantation in children.

F M KARRER Assistant Professor of Surgery

J R LILLY Professor

Children's Hospital,

Denver, Colorado 80218, USA 
1 Salt A, Noble-Jamieson G, Barnes ND, Mowat AP, Rolles K, Jamieson N, et al. Liver transplantation in 100 children: Cambridge and King's College Hospital series. BMF 1992;304: 416-21.

2 Starzl TE, Gordon RD, Iwatsuki S. Liver transplantation in children-a solution for biliary atresia? In: Surgical diseases of the liver in childhood. Chicago: American College of Surgeons, 1985:17-8.

3 Wood RP, Langnas AN, Stratta RJ, Pillar TJ, Williams M, Lindsay S, et al. Optimal therapy for patients with biliary atresia: portoenterostomy ("Kasai" procedures) versus primary transplantation. F Pediatr Surg 1990;25:153-60.

4 Lilly JR, Karrer FM, Hall RJ, Stellin GD, Vasquez-Estevez JJ, Greenholz SK, et al. The surgery of biliary atresia. Ann Surg 1989;210:289-96.

5 Esquivel CO, Koneru B, Karrer FM, Todo S, Iwatsuki S, Gordon R, et al. Liver transplantation before one year of age. F Pediatr 1987;110:545-8.
6 Ryckman FC, Flake AW, Fisher RA, Tchervenkov JI, Pedersen SM, Balistrari WF, et al. Segmental orthotopic hepatic transplantation as a means to improve patient survival and diminish waiting-lis mortality. F Pediatr Surg 1991;26:422-7.

7 Kolayoglu M, D'Alessandro AM, Sollinger HW, Hoffman RM, Pirsch JD, Belzen FO, et al. Experience with reduced-size liver transplantation. Surg Gynecol Obstet 1990;171:139-47.

8 Thistlethwaite JR Jr, Emond JC, Woodle ES, Vogelbach P, Black DD, Whitington PF, et al. Increased utilization of organ donors: transplantation of two recipients from single donor livers. Transplant Proc 1990;22:1485-6.

9 Droelach CE, Whitington PF, Emond JC, Heffron TG, Thistlethwaite JR, Stens L, et al. Live transplantation in children from living related donors. Surgical techniques and results. Ann Surg 1991;214:428-39.

\section{Fundholding general practices}

\section{Early successes - but will they last?}

This week sees the publication of a report on the experience of 10 first wave fundholding practices, charting their progress through the preparatory year and the first three months of the scheme. ${ }^{1}$ These pioneers took charge of budgets covering practice and prescribing costs and a range of hospital services. They were able to use their leverage to extract advantages in hospital contracts, including shorter waiting times and faster turn around of pathology tests (by switching providers, buying extra sessions, or pressurising local hospitals).

Some cut costs by switching to generic prescribing, reducing referrals, or changing providers. These savings were used to develop practice based services, such as consultant clinics and physiotherapy sessions. In some cases practices pooled resources to pay for the reopening of closed wards in their local hospitals. Despite numerous teething problems the first wave fundholders were enthusiastic about the benefits of the scheme three months on.

Buoyed by this apparent success, the secretary of state has announced the extension of the scheme to smaller practices. Before getting carried away on a tide of euphoria about the benefits of a demand led service it is worth stopping to ponder whether these early advantages can be sustained and to consider the risks inherent in the scheme. So far the major achievements have lain in the improvements in quality that fundholders have extracted from hospitals. The practice based innovations are important too, though none is unique to fundholding: many non-fundholders have developed generic prescribing policies, computerised information systems, specialist clinics, minor surgery sessions, diagnostic facilities, and protocols for shared care.

Though hospitals woke up to fundholding very late in the day, most have shown a new willingness to negotiate with general practitioners. This represents a breakthrough for secondary care, which has often been unresponsive to consumer concerns. Supporters of fundholding argue that district health authorities can never match general practitioners' sensitivity to patients' requirements. Certainly fundholders led the way in negotiating detailed quality specification in their hospital contracts, but many health authorities are now taking considerable pains to determine the views of general practitioners so as to redress the balance. ${ }^{2}$

Much of the concern about the scheme centres on the extent to which the advantages for the patients of fundholding practices are gained at the expense of those whose practices do not hold budgets, thus increasing inequalities. Glennerster and colleagues argue that improvements may result from improved efficiency, which may benefit all practices. ${ }^{1}$ Unfortunately, their study does not include non-fundholding practices, so we shall have to look elsewhere to test this assertion. True or not, it highlights a key political issue, for as long as fundholders remain a small minority of well organised larger practices, with good facilities mostly in prosperous areas, they will be open to the charge that the scheme channels resources to those areas least in need.

Several large problems remain. One of the most intractable concerns the allocation of budgets. At present budgets are based on past patterns of service use, which is unsatisfactory for several reasons. Firstly, it was extremely difficult to determine the extent of past activity because of inadequate routine data. Secondly, it is now well established that rates of referral and admission vary widely among practices, ${ }^{3}$ and these variations remain unexplained by conventional measures of need. ${ }^{45}$ Budgets allocated to the fledgling fundholders varied by a factor of three, partly for this reason and partly because hospital prices varied widely. ${ }^{6}$ Thirdly, this method of allocating budgets provides an incentive for practices to increase their rates of prescribing and referral in the preparatory year and penalises those practices that are already efficient. The fourth and most worrying problem is that practices may be persuaded to indulge in "cream skimming," whereby patients with expensive health care needs are removed from their lists.?

To counteract these problems the Department of Health is anxious to move towards formula based funding, although constructing a satisfactory formula is proving difficult. An important problem concerns the use of private medical care. In the Oxford region referrals to private clinics ranged from less than $5 \%$ to more than $50 \%$ of practices' total outpatient referrals. ${ }^{8}$ No data are collected on numbers of patients with private health insurance, or on clinical activity in independent hospitals. Unless the formula can take account of these, practices in prosperous areas will continue to have a financial advantage over others.

Other concerns include the potential for abuse arising from the fact that practices have been allowed to establish private companies to enable them to sell and buy services from themselves. When this occurs the competitive advantages of the purchaser-provider split no longer apply. Practices that have established their own locally based services-for example, physiotherapy-dramatically increase their referrals to these facilities. Is this evidence of previously unmet need or of demand induced by suppliers? How can we be sure that patients are receiving the best care? As the American experience shows, preventing abuse will require careful regulation.

The future of fundholding is hard to predict, not least because Labour has pledged to abandon the scheme if it wins the election. The first year of fundholding may not turn out to be typical: whereas fundholders could play the market district purchasers had to keep to historical referral patterns. If health authorities' future purchasing plans closely reflect general practitioners' wishes practices may see little advantage in 